\title{
Basal melting at the Ekström Ice Shelf, Antarctica, estimated from mass flux divergence
}

\author{
Niklas NECKEL, ${ }^{1 *}$ Reinhard DREWS, ${ }^{1 \dagger}$ Wolfgang RACK, ${ }^{2}$ Daniel STEINHAGE ${ }^{1}$ \\ ${ }^{1}$ Alfred Wegener Institute for Polar and Marine Research, Bremerhaven, Germany \\ E-mail: Niklas.Neckel@awi.de \\ ${ }^{2}$ Gateway Antarctica, University of Canterbury, Christchurch, New Zealand
}

\begin{abstract}
We characterize the basal mass balance of the Ekström Ice Shelf, Dronning Maud Land, Antarctica, using interferometrically derived surface velocities and ice thickness measurements from radio-echo sounding (RES). The surface velocities are based on data from European Remote-sensing Satellites-1 and -2 (ERS-1/2) during 1994-97. The ice thickness grid consists of 136 RES profiles acquired between 1996 and 2006. Mass fluxes are calculated along selected RES profiles where possible, to reduce uncertainties from ice thickness interpolation. Elsewhere large-scale mass fluxes are calculated using interpolated ice thickness data. The mass flux into the Ekström Ice Shelf from the main grounded drainage basins is estimated to be $3.19 \pm 0.4 \mathrm{Gta}^{-1}$. The mass flux near the ice shelf front is $2.67 \pm 0.3 \mathrm{Gta}^{-1}$. Assuming steady state, and based on the equation of continuity, we interpret the residual mass flux as a combined effect of snow accumulation and subglacial melting/refreezing. Using net snow accumulation rates from previous studies, we link the mass flux divergence in irregular-shaped polygons to processes beneath the ice shelf. The highest subglacial melt rates of $\sim 1.1 \mathrm{~m} \mathrm{a}^{-1}$ are found near the grounding zone of two main inflow glaciers, and around the German station Neumayer III. The detection of unlikely refreezing in a small area $\sim 15 \mathrm{~km}$ west of Neumayer III is attributed to both dataset inaccuracies and a (possibly past) violation of the steady-state assumption. In general, the method and input data allow mapping of the spatial distribution of basal melting and the results are in good agreement with several previous studies.
\end{abstract}

\section{INTRODUCTION}

About three-quarters of the Antarctic ice sheet's perimeter consists of floating ice (Bindschadler and others, 2011). Ice shelves and ice tongues link the grounded ice sheet to the Southern Ocean. Associated melting and freezing at their base plays an important role in the overall ice-sheet/iceshelf mass balance, as well as in ocean processes (Hellmer, 2004; Payne and others, 2004; Jenkins and others, 2010). The coastline of Dronning Maud Land between $27^{\circ} \mathrm{W}$ and $33^{\circ} \mathrm{E}$ is largely in the Atlantic sector of Antarctica and almost entirely bordered by a number of comparatively small ice shelves. The Ekström Ice Shelf is a typical ice shelf for this coast. It is confined by the ice ridges Søråsen in the west and Halvfarryggen in the east (Fig. 1a) and covers an area of $\sim 6800 \mathrm{~km}^{2}$ (area measured between the grounding line given by Bindschadler and others (2011) and the ice-shelf front). The narrow continental shelf in this area permits a strong interaction between ice-shelf water and the coastal current and associated heat transports into the ice-shelf cavity (Nicolaus and Grosfeld, 2002). This characteristic geographic setting could make ice shelves in this location particularly susceptible to rising ocean temperatures, either by ocean warming (Gille, 2008) or increased upwelling of warm Circumpolar Deep Water (Holland and others, 2008). However, the relevance and magnitude of these effects for additional melting under specific ice shelves (like the Ekström Ice Shelf) is uncertain, because basal melting also

\footnotetext{
*Present address: Institute of Geography, University of Tübingen, Tübingen, Germany.

†Present address: Laboratoire de Glaciologie, Université Libre de Bruxelles, Bruxelles, Belgium.
}

depends on ice-shelf morphology (Little and others, 2009). So far, no unusual changes in ice-shelf geometry along this coast have been observed; however, direct and indirect estimations of basal mass balance are scarce.

Because in situ measurements of basal mass balance of ice shelves are spatially limited and involve high costs and large logistical efforts, remote-sensing methods may play a central role in achieving this goal. The most accurate (indirect) measurement of basal melt to date requires phasesensitive radar at the surface, which measures basal ablation at an accuracy of a fraction of the applied radar wavelength (Corr and others, 2002). Such measurements, carried out in a Lagrangian coordinate system flowing with the ice, have been achieved at only a few points so far, as they require redeployment of the radar antenna in exactly the same surface position after a prolonged time period. They also require measurements of strain rates at the same location to account for ice thickness change by deformation. A spatial distribution of basal mass balance in a fixed Eulerian coordinate system can be indirectly estimated for an ice shelf in equilibrium state using the mass-continuity assumption (e.g. Joughin and Padman, 2003; Wen and others, 2010), a concept which we pursue in this work. This requires high-quality datasets of ice velocity, ice thickness and snow accumulation, as small uncertainties in the input data are more likely to dominate the residual mass flux.

We can make use of high-quality input datasets at the Ekström Ice Shelf, in the immediate neighborhood of the German station Neumayer III $\left(70.67^{\circ} \mathrm{S}, 8.27^{\circ} \mathrm{W}\right)$. This ice shelf has been the location of the German overwintering stations since 1980 and is well surveyed, unlike many other ice shelves. We make use of published data on surface 

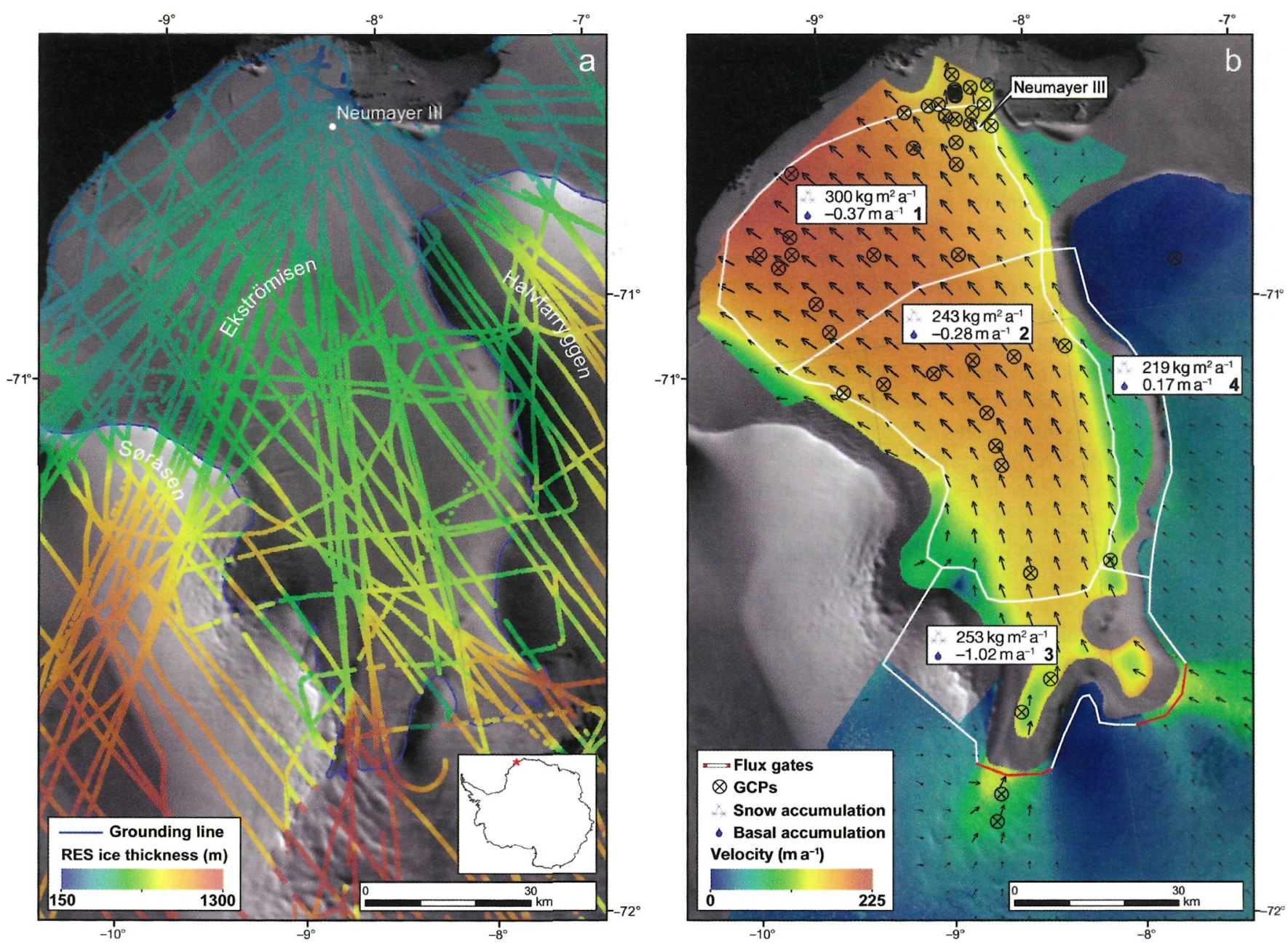

Fig. 1. (a) Region of interest, with ice thickness profiles from RES and grounding line estimate as published by Bindschadler and others (2011). (b) Interferometric SAR (InSAR)-derived velocity field, location of GCPs and estimated large-scale surface and basal mass balance. Both maps are based on the Moderate Resolution Imaging Spectroradiometer (MODIS) Mosaic of Antarctica (Haran and others, 2006).

mass balance and in situ surface velocity measurements. The core of our analysis is based on European Remote-sensing Satellite-1 and -2 (ERS-1/2) synthetic aperture radar (SAR) interferometric data providing area-wide surface velocities, and ice thickness measurements from radio-echo sounding (RES) surveys. We also investigate the limitations of the mass flux divergence method when applied to small ice shelves with typical input data such as these.

The rest of the paper is organized as follows: Section 2 presents a review of related measurements over the past 30 years in our area of interest. In situ measurements serve as ground control for the satellite analysis, and support the assumption that the Ekström Ice Shelf is in a steady state. Section 3 describes the discretization and implementation of the continuity equation, as well as the derivation of the input datasets, such as the surface velocity field, ice thickness and surface balance data. In Sections 4 and 5 the results for the basal mass balance and the expected accuracy are presented and discussed.

\section{PREVIOUS STUDIES}

For the Ekström Ice Shelf area, Hinze (1990) published 52 in situ velocity measurements from different campaigns between 1979 and 1987 using Navy Navigation Satellite System (NNSS) and GPS measurements. He provided error estimates of $<15 \mathrm{ma}^{-1}$ in magnitude and $\pm 2^{\circ}$ in flow direction. Some of these measurements were excluded from our study as they do not cover the area of investigation. In 1997, the tidal deformation of the ice-shelf surface in the southern part of the Ekström Ice Shelf was investigated and flow velocities were derived on grounded and floating ice by GPS measurements (Riedel and Vogel, 1998). Near the seismic observatory on the northwestern flank of Halvfarryggen an additional GPS velocity measurement from 2007 was provided by C. Wesche (unpublished data). Assuming steady-state conditions, the different datasets are considered suitable to serve as ground-control points (GCPs) for the interferometric analysis (see Fig. $1 \mathrm{~b}$ for the respective locations).

Snow accumulation estimates from snow pits and firn and ice-core drillings were interpolated to an accumulation map for western Dronning Maud Land by Rotschky and others (2007). Ice thickness has been measured using RES since the 1980s (Thyssen and Grosfeld, 1988). We used ice thickness measurements from 1996 to 2006 (Fig. 1a) and the snow accumulation estimates of Rotschky and others (2007); both datasets are discussed in the next section.

Maps of surface elevation, ice thickness and estimated subglacial topography of the Ekström Ice Shelf and its catchment area were published by Sandhäger and Blindow (2000). Based on these datasets and measured snow accumulation 
rates, they calculated an ice flux of $\sim 3.7 \mathrm{Gta}^{-1}$ from the drainage basin into the Ekström Ice Shelf. Müller and others (2000) estimated a seaward ice flux of $2.7 \mathrm{~km}^{3} \mathrm{a}^{-1}$ $\left(\sim 2.5 \mathrm{Gta}^{-1}\right)$ by combining RES measured ice thickness data and advance rates of the ice-shelf front, derived from Landsat MSS (multispectral scanner) and ERS imagery. On the basis of both studies it is assumed that basal melting exceeds snow accumulation in the Ekström Ice Shelf region.

Using a three-dimensional (3-D) ice-shelf flow model, Sandhäger (2000) estimated an average basal melt rate of $0.53 \mathrm{~m} \mathrm{a}^{-1}$. Nicolaus and Grosfeld (2002) employed a 3-D ocean circulation model and obtained an average basal melt rate of $0.98 \mathrm{~m} \mathrm{a}^{-1}$ for the Ekström Ice Shelf. For the grounding zone region they estimated melt rates of up to $14 \mathrm{~m} \mathrm{a}^{-1}$.

In 1993, several access holes were drilled through the Ekström Ice Shelf next to Neumayer base. In order to record the ablation rates at the ice-shelf bottom an ultrasonic echosounder was installed in one of these boreholes (Nixdorf and others, 1994; Lambrecht and others, 1995). The average melting rates were $\sim 0.9 \mathrm{ma}^{-1}$ at this location, which is marked as a white dot in Figure 3.

Kipfstuhl (1991) calculated melt rates based on the equation of continuity, at selected points along an approximated flowline (points marked as black dots in Fig. 3) using GPS-derived surface velocities. Interpolated ice thickness data were compiled from airborne RES measurements, and snow accumulation rates were taken from measurements at Neumayer base. Basal melt rates of $\geq 2 \mathrm{~m} \mathrm{a}^{-1}$ were estimated near the grounding line, $0.2 \mathrm{~m} \mathrm{a}^{-1}$ in the central part of the ice shelf and $1.15 \mathrm{~m} \mathrm{a}^{-1}$ near the ice-shelf front.

\section{DATA AND METHODS}

Assuming the Ekström Ice Shelf is in steady state, basal melt rates, $\dot{a}_{b}$, can be estimated from the equation of continuity,

$$
\dot{a}_{\mathrm{b}}=\nabla \cdot(H \mathbf{v})-\dot{a}_{\mathrm{s}}
$$

in which $\dot{a}_{s}$ is the surface balance term (positive for mass gain), $H$ is the ice thickness and $\mathbf{v}$ is the ice velocity. A constant vertical velocity profile is assumed for the floating ice shelf in the absence of basal friction. The implementation of the spatial derivative varies between applications. In a numerical sense, it can simply be discretized on the respective gridcells of the input variables using different discretization schemes. In a budgeting sense, it can be calculated along the perimeter of arbitrarily closed shapes. Often polygons (regular- or irregular-shaped 'boxes') are chosen which are somewhat aligned with the main flow direction. The difference between incoming and outgoing mass flux is then given by the sum of surface and basal accumulation over the enclosed area. Where flux gates are chosen along a flowline, the precondition of closed shapes can be dropped. This is an attractive choice for the application of the continuity equation in field measurements (e.g. Jenkins and Doake, 1991; Kipfstuhl, 1991). Although the implementation in a numerical sense and in a budgeting sense average over areas of different size, they do not differ in principle. Both methods blend into each other if the circumference of the polygons (i.e. the box size) is chosen to be of a similar order of magnitude to the pixel spacing in the respective discretization scheme. Since the acquired datasets are usually on different grids at first, it is tempting to subsample all data to the highest spatially resolved dataset (typically the interferometrically derived flow velocities), and then use the numerical derivation as it offers the highest spatial resolution. Previous analysis using a similar approach (Morlighem and others, 2011; Seroussi and others, 2011) found that the gridding of the input data plays an important role. Subsampling of the ice thickness grid in particular can introduce severe artifacts. To avoid this problem, the spatial resolution of the input datasets is commonly reduced (e.g. to the mean spacing of available RES lines). The question remains, however, what is the best spatial resolution that can safely be achieved? This is addressed after the next three subsections, which describe the derivation of surface velocity, ice thickness and snow accumulation data.

\subsection{Surface velocities}

Surface velocities were derived from ERS-1/2 repeat-pass SAR interferometry with the aid of the GAMMA SAR and interferometric processing software (Werner and others, 2000). Two 'topography-free' interferograms, one from a descending and one from an ascending satellite pass, were combined under the assumption of surface-parallel ice flow, in order to measure the full 3-D surface displacement. This method is now routinely employed to measure glacial movement (e.g. Joughin and others, 1998). The topographic contributions over grounded ice were removed using a local digital elevation model (DEM) derived in a previous study by differential SAR interferometry (Drews and others, 2009). As this DEM excludes the floating ice shelf, elevation data from an altimetric DEM were used to remove the topographicinduced phase difference in this region. For the grounded part of our area of interest, the local DEM of Wesche (2009) includes more data points for the interpolation than the Antarctic-wide DEM of Bamber and others (2009). However, for the floating ice shelf, we chose the Bamber DEM over the DEM of Wesche (2009), because the resulting flow velocities showed a smaller standard deviation from the available velocity GCPs.

The SAR scenes used to derive surface velocities are listed in Table 1. Of the available coherent image pairs, preference was given to those with a short spatial baseline, to decrease the sensitivity to topography. The spatial baseline was estimated from precise orbit data provided by the Delft Institute for Earth-oriented Space Research. The relative unwrapped phase difference of the individual interferograms was turned into absolute values by offsetting the interferograms against a velocity GCP within the scene. For this step, the velocities of the respective GCPs were translated into a motion-induced phase difference along the satellite's look vector, using the orbital parameters of the corresponding interferograms. The relatively large baseline of track 493 was additionally refined with a least-squares fit based on several velocity GCPs. The baselines of the other satellite tracks were either too short for such a refinement or insufficient GCPs were available.

Tidal movement between data acquisitions is reflected in an interferogram by a high phase gradient in the grounding zone, where the horizontal ice flow is overlaid by differential vertical displacement. On the one hand, this makes SAR interferometry a powerful tool for grounding zone detection (e.g. Sykes and others, 2009; Rignot and others, 2011) but, on the other hand, no horizontal displacement can be safely derived in this region. We identified the zone of strong tidal flexure by the dense fringe pattern in the interferogram of track 493 . It is shown as a gap of $\sim 5 \mathrm{~km}$ width in the velocity field in Figure $1 \mathrm{~b}$. For the calculation of mass flux, 
Table 1. Overview of ERS tracks, frames, date of data acquisition, perpendicular baseline, $B_{\perp}$, and satellite pass

\begin{tabular}{lccrc}
\hline Track & Frame & Date & $B_{\perp}(\mathrm{m})$ & Pass \\
\hline 021 & 5085 & 2/5 March 1994 & 14 & descend. \\
221 & 5121,5103 & 5/6 March 1996 & 233 & descend. \\
493 & $5121,5103,5085$ & 18/19 February 1996 & 214 & descend. \\
002 & 5697 & 15/16 January 1996 & 50 & ascend. \\
031 & $5661,5679,5697$ & 6/9 March 1994 & 48 & ascend. \\
045 & $5661,5679,5697$ & 13/14 Mar 1997 & 193 & ascend. \\
460 & 5715 & 22/23 Mar 1996 & 23 & ascend. \\
\hline
\end{tabular}

we positioned the flux gates at a distance of $\geq 7 \mathrm{~km}$ from the grounding line. Assuming that the remainder of the ice shelf is lowered and lifted uniformly, the vertical displacement for the freely floating parts cancels by offsetting the unwrapped phase to a velocity GCP.

The individual flow fields were mosaicked and sampled to a $100 \mathrm{~m} \times 100 \mathrm{~m}$ grid. In overlapping areas the difference of individually processed flow fields is a first estimate for the overall accuracy. On the grounded part, overlapping edges differ between 1 and $35 \mathrm{ma}^{-1}$. For the floating parts the difference between the northern frames (combination from tracks 021 and 460) and the southern frames (combination from tracks 493 and 002) is a constant offset of $\sim-22 \mathrm{~m} \mathrm{a}^{-1}$. We attribute this offset to the northern flow field, as a similar offset is evident in a comparison with the (northern) GCPs, while no systematic offset is observed for the southern track combination. Neglecting the origin of this difference (e.g. atmospheric contribution, imprecise baseline estimates, tidal movement), we offset the northern flow field and feather remaining differences with a distance-weighted blend routine. To estimate the error, we compare the velocity map with all available GCPs (Fig. 2) excluding the ones used for offsetting the interferograms. The GCPs which were used for the baseline refinement of track 493 were included, as the baseline refinement is not a direct fit to the GCPs but an adjustment of the baseline model. Mean and standard deviation compared with the velocity at the GCPs are $4 \pm 18 \mathrm{ma}^{-1}$ in magnitude and $12 \pm 8^{\circ}$ in flow direction. As shown in Figure 2, the deviation in magnitude is not correlated with the location.

\subsection{Ice thickness}

The airborne ice thickness data were acquired between 1996 and 2006 in various campaigns. Characteristics of the pulsed RES system are described by Nixdorf and others (1997) and Steinhage and others (2001). The center frequency of the emitted bursts is $150 \mathrm{MHz}$, and the pulse length can be toggled between 60 and $600 \mathrm{~ns}$. The short pulse is suited for applications which require a higher vertical resolution (and less penetration depth), whereas the long pulse aims to increase the penetration depth (while decreasing the vertical resolution). The dataset presented here is based on both modes, since some RES profiles are only available with the long pulse. However, considering the ice thicknesses encountered, the short pulse is the more appropriate choice for sounding the ice shelf. Data processing varies slightly between the profiles acquired in different seasons. Standard processing encompasses tenfold stacking, differentiation, bandpass filtering and an automatic

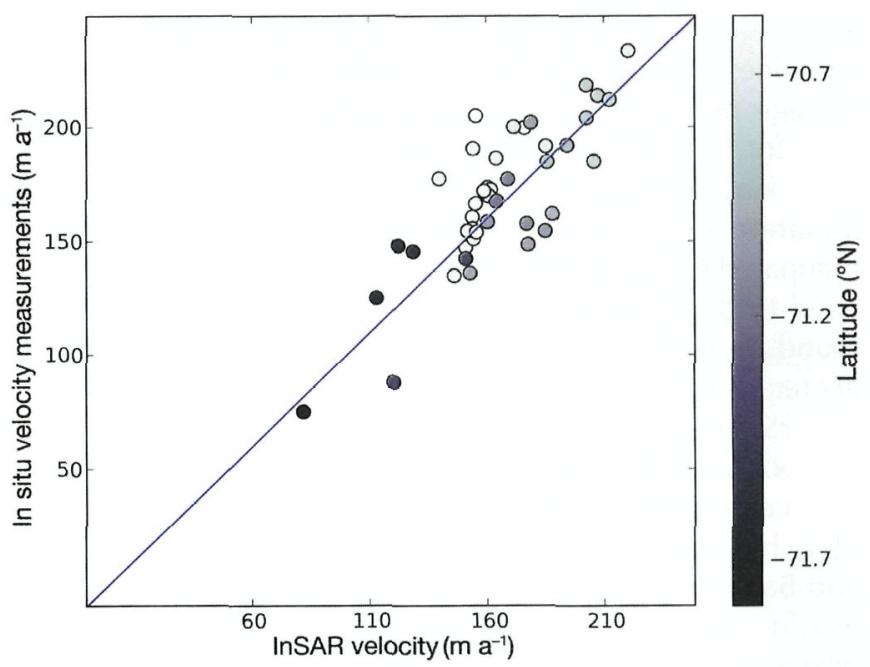

Fig. 2. Deviation between InSAR-derived surface velocities and in situ measured surface velocities. The error in magnitude is $4 \pm 18 \mathrm{~m} \mathrm{a}^{-1}$. Latitude value of GCPs is grayscaled.

gain control (Steinhage and others, 1999). The horizontal shot spacing of the stacked data depends on the flight speed, but generally varies between 20 and $30 \mathrm{~m}$. The travel-time to depth conversion uses a constant propagation velocity of $168 \mathrm{~m} \mathrm{us}^{-1}$ in ice, and includes a firn correction of $8 \mathrm{~m}$ to account for a higher radar velocity in firn. We use these values based on a column-averaged ice density of $878 \mathrm{~kg} \mathrm{~m}^{-3}$, which is estimated after modeling studies by Ligtenberg and others (2011). The firn correction is similar to the firn correction of $8.8 \mathrm{~m}$ derived from common-midpoint measurements by Blindow (1994) on the Filchner-Ronne Ice Shelf. Profiles crossing large crevasses at the surface (especially in the northwestern part of the Ekström Ice Shelf) show a characteristic upward bending of the bottom reflection. This originates from less consolidated snow and ice filling the crevasses, which results in a faster signal propagation. This is not accounted for with the constant firn correction. These features were removed manually, and gaps were closed with an inverse distance-weighting interpolation scheme.

In terms of deriving the ice thickness, the bottom reflection from ice shelves is ambiguous because it does not necessarily originate from the ice/ocean interface, but rather represents the boundary of meteoric and (refrozen) marine ice. Previous studies (Thyssen, 1988; Jenkins and Doake, 1991; Blindow, 1994) investigated the marine/meteoric boundary and concluded that this internal reflection appears strongly. Depending on the thickness of the marine ice layer, the ice/ocean interface is potentially masked, due to increased signal attenuation in the marine bottom layer. The total ice thickness is often inferred via a hydrostatic inversion scheme, which combines the freeboard height with a density/depth profile (e.g. Fricker and others, 2001; Lambrecht and others, 2007; Wen and others, 2010). Unlike the larger Antarctic ice shelves, the comparatively small Ekström Ice Shelf shows no signs of accreted ice, and we argue that the RES lines considered here indeed image the ice/ocean interface, and thus reflect the total ice thickness. The argument is three-fold: (1) Modeling studies (Nicolaus and Grosfeld, 2002) of the ocean circulation beneath the Ekström Ice Shelf predict the highest melt rates near the grounding line, but no accretion 
anywhere on the ice shelf. (2) The bottom reflection in the RES lines appears specular, laterally smoothed and shows no sign of a second reflector at greater depths. This is the case for both the long and short pulse. We would expect some kind of penetration, at least for the long-pulse datasets, if marine ice were present. (3) Thyssen and Grosfeld (1988) compared the RES-inferred ice thickness over the Ekström Ice Shelf to those inferred from a hydrostatic equilibrium and found no positive anomalies, therefore concluding that no accreted ice is present. Similarly, in an enhanced dataset of RES lines, Sandhäger and Blindow (2000) interpreted the bottom reflection from the Ekström Ice Shelf as the ice/ocean interface. It should be noted that a comparison of a hydrostatic inverted ice thickness map from Griggs and Bamber (2011) with our interpolated ice thickness map would suggest that marine ice is present. However, this observed difference is small (mean and standard deviation of $8 \pm 22 \mathrm{~m}$ ) and is believed to originate from uncertainties in surface elevation and ice and sea-water densities (for error propagation see Griggs and Bamber, 2011), rather than from the presence of marine ice. This becomes evident near Neumayer station where in situ measurements by Lambrecht and others (1995) show basal melting, whereas the difference of RES and hydrostatically inverted ice thickness indicates accretion. Based on previous studies and our own analysis we therefore conclude that the RES ice thickness map actually represents the total ice thickness and is not flawed by an undetected marine ice layer.

\subsection{Surface mass balance}

The surface mass balance at the Ekström Ice Shelf is comparably well investigated (Schlosser and others, 1999). The mean net snow accumulation (referred to as 'snow accumulation' in this paper) is that of Rotschky and others (2007), who derived an accumulation map for western Dronning Maud Land from snow-pit samples and firnand ice-core drillings. By comparison with new firn cores, it is now known that the map underestimates the snow accumulation on the summit of Halvfarryggen by up to $1012 \mathrm{~kg} \mathrm{~m}^{-2} \mathrm{a}^{-1}$ (Fernandoy and others, 2010). This is because, for Halvfarryggen, only one tie-point was available to Rotschky and others (2007), which is located $\sim 36 \mathrm{~km}$ northwest of the summit. For the Ekström Ice Shelf, six tie points were available (see fig. 3 of Rotschky and others, 2007) and the map shows quite a homogeneous accumulation pattern, with values between 210 and $360 \mathrm{~kg} \mathrm{~m}^{-2} \mathrm{a}^{-1}$. Higher values are observed in the northeast of the ice shelf near Neumayer station, and lower values in the south near the grounding line. Shadowing effects are visible near Halvfarryggen as a result of dominant winds from the east (König-Langlo and Loose, 2007). Rotschky and others (2007) applied their interpolation scheme with ten different settings, resulting in a standard deviation from the mean of only $2.5 \mathrm{~kg} \mathrm{~m}^{-2} \mathrm{a}^{-1}$ at the ice shelf. This low value indicates a robust interpolation in this area. We compared the map to the multi-year averages in snow accumulation at the six tie points used by Rotschky and others (2007) and obtained a mean difference of $-8.2 \pm 21.1 \mathrm{~kg} \mathrm{~m}^{-2} \mathrm{a}^{-1}$. After a bias correction of $+8.2 \mathrm{~kg} \mathrm{~m}^{-2} \mathrm{a}^{-1}$ we considered the accumulation map suitable for our purpose.

\subsection{Quantification of subglacial melting}

In order to get a large-scale estimate of basal melting beneath the Ekström Ice Shelf we calculated the residual mass flux,
$F$, along the perimeter of the polygons shown in Figure $1 \mathrm{~b}$, using interpolated ice thickness data on a $5 \mathrm{~km} \times 5 \mathrm{~km}$ grid. $F$ is calculated as the cumulative sum of the mass flux, $f_{i}$, across the individual pixels, $i$,

$$
F=\sum_{i=2}^{i=N-1} f_{i}=\sum_{i=2}^{i=N-1} v_{i} \cdot \cos \left(\phi_{i}^{\prime}\right) \cdot H_{i} \cdot d_{i}
$$

where $N$ is the number of pixels in the flux gate and $\phi_{i}^{\prime}$ is the normal angle to the flux gate at position $i$, which is calculated to be perpendicular to the line connecting positions $i+1$ and $i-1$. The pixel spacing is indicated by $d_{i}$. For the conversion between volume and mass we used the column-averaged ice density of $878 \mathrm{~kg} \mathrm{~m}^{-3}$ based on modeling studies of Ligtenberg and others (2011). As the flux gates on the grounded ice are near the grounding line, basal sliding is assumed in this region. Therefore, $v_{i}$ is estimated to equal the surface velocity for all flux gates.

Following the budgeting approach, the difference between incoming and outgoing fluxes, $F$, of each polygon is determined by $\dot{a}_{s}+\dot{a}_{b}$. Whether $F$ represents incoming or outgoing flux is defined by the algebraic sign of $\cos \left(\phi_{i}^{\prime}\right)$, therefore $\dot{a}_{b}$ can simply be calculated by

$$
\dot{a}_{\mathrm{b}}=\frac{F}{A}-\dot{a}_{\mathrm{s}}
$$

where $F$ is calculated along the perimeter of a polygon enclosing the area $A$.

To evaluate the spatial distribution of basal melting on a finer scale, we averaged the RES data (mean shot spacing $\sim 30 \mathrm{~m}$ ) along the profiles at the same gridcell spacing as the surface velocities (grid spacing $100 \mathrm{~m}$ ). The intersecting RES lines form polygons (black lines in Fig. 3) which we used to estimate $\dot{a}_{\mathrm{b}}$, in the same way as demonstrated above. The resulting melt rates of each polygon were interpolated across the ice shelf using an inverse distance-weighted interpolation scheme. Choosing the polygons along the RES flight tracks avoids interpolation of the RES data and any associated artifacts.

\section{RESULTS}

The main flux from the main grounded catchment basins into areas 3 and 4 of the Ekström Ice Shelf (Fig. 1b) is estimated to be $3.19 \pm 0.4 \mathrm{Gta}^{-1}$. This is calculated from the analyzed surface velocities and ice thickness along the line on grounded ice shown in Figure $1 \mathrm{~b}$ assuming full sliding. The mass flux leaving area 1 (Fig. 1b) is estimated to be $2.67 \pm 0.3 \mathrm{Gta}^{-1}$. Table 2 lists the estimated incoming and outgoing fluxes for the four polygons shown in Figure $1 \mathrm{~b}$ and the resulting melt rates. Uncertainties are larger for polygons 3 and 4 because no InSAR surface velocities are available in the grounding zone. The positive value for polygon 4 is smaller than the error boundary, so a small basal melting is also possible. The interpolated melt rates for the polygons along the RES flight tracks are shown in Figure 3, and error estimates are discussed in the following section.

We compared our results to previous estimates of Kipfstuhl (1991) and Lambrecht and others (1995). The different values are listed in Table 3. The ultrasonic measurements of Lambrecht and others (1995) near Neumayer base are the only direct ground truth to validate our approach. The basal melt rates derived by Kipfstuhl (1991) are based on an interpolated ice thickness map and the assumption that 


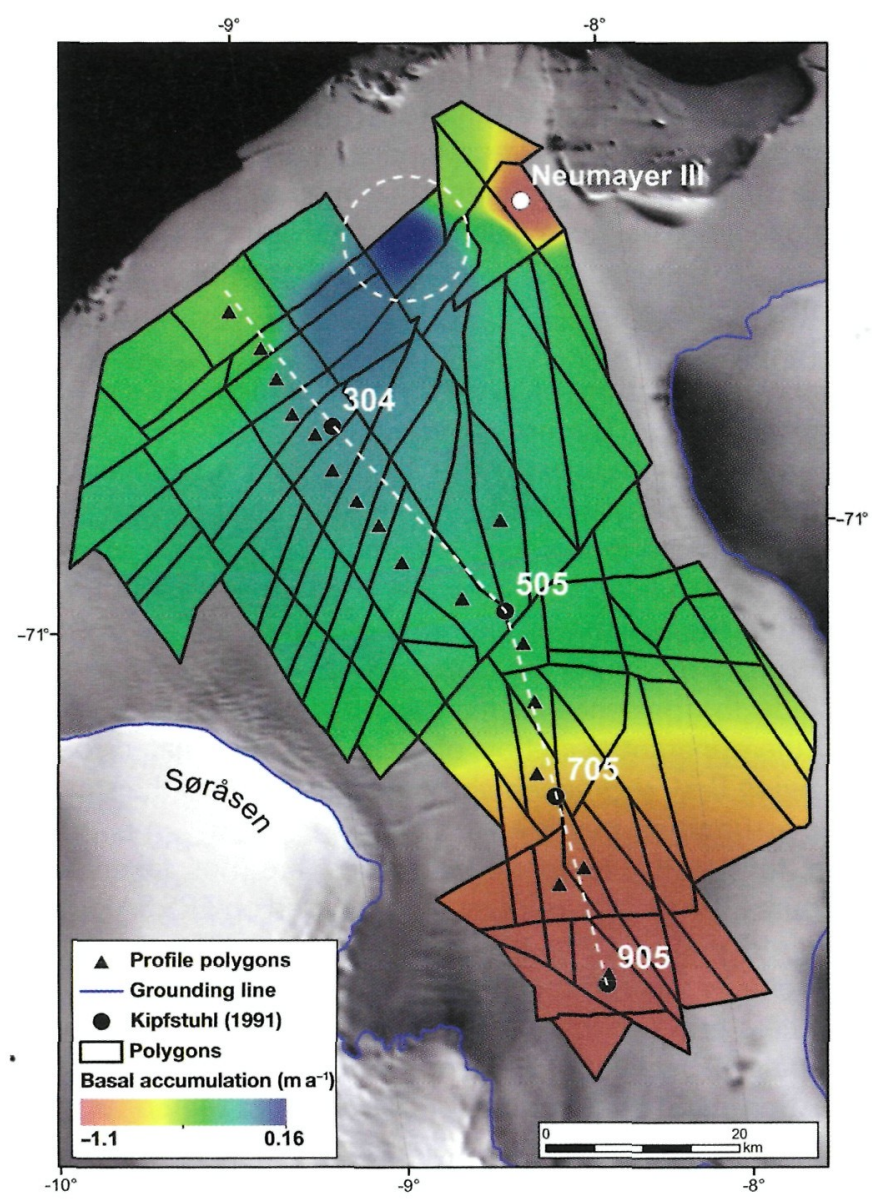

Fig. 3. Model output for closed boxes along the flown RES tracks. Grounding-line estimate by Bindschadler and others (2011).

the two available velocity measurements for each point were aligned along a flowline. In that approach, errors can arise from neglecting transverse strain, interpolating RES lines or assuming that the snow accumulation at the individual sites equals the accumulation rate measured at Neumayer base.

\section{DISCUSSION}

Using the continuity equation to infer basal melt rates is based on the reliable determination of spatial changes in snow accumulation and mass flux. Precise absolute values are required, in terms of snow accumulation, while in terms

Table 2. Estimated ice flux, mean snow accumulation, $\dot{a}_{s}$, size and estimated basal accumulation, $\dot{a}_{\mathrm{b}}$, for the polygons shown in Figure $1 b$. For better comparison with Figure $1 b, \dot{a}_{b}$ is also given in $\mathrm{ma}^{-1}$

\begin{tabular}{|c|c|c|c|c|}
\hline & \multicolumn{4}{|c|}{ Polygon (area) } \\
\hline & $\begin{array}{c}1 \\
\left(1718 \mathrm{~km}^{2}\right)\end{array}$ & $\begin{array}{c}2 \\
\left(2089 \mathrm{~km}^{2}\right)\end{array}$ & $\begin{array}{c}3 \\
\left(1302 \mathrm{~km}^{2}\right)\end{array}$ & $\begin{array}{c}4 \\
\left(524 \mathrm{~km}^{2}\right)\end{array}$ \\
\hline In-flux $\left(\mathrm{Gt} \mathrm{a}^{-1}\right)$ & 2.71 & 2.59 & $2.54^{*}$ & 0.65 \\
\hline Out-flux $\left(\mathrm{Gt} \mathrm{a}^{-1}\right)$ & 2.67 & 2.58 & 1.68 & 0.85 \\
\hline$\dot{a}_{\mathrm{s}}\left(\mathrm{Gta}^{-1}\right)$ & 0.51 & 0.50 & 0.33 & 0.12 \\
\hline$\dot{a}_{\mathrm{b}}\left(\mathrm{Gta}^{-1}\right)$ & -0.55 & -0.51 & -1.16 & 0.08 \\
\hline$\dot{a}_{b}\left(m^{-1}\right)$ & -0.37 & -0.28 & -1.02 & 0.17 \\
\hline
\end{tabular}

*Including an ice flux of 1.11 and $0.94 \mathrm{Gta}^{-1}$ across the western and eastern flux gates (red in Fig. 1b).

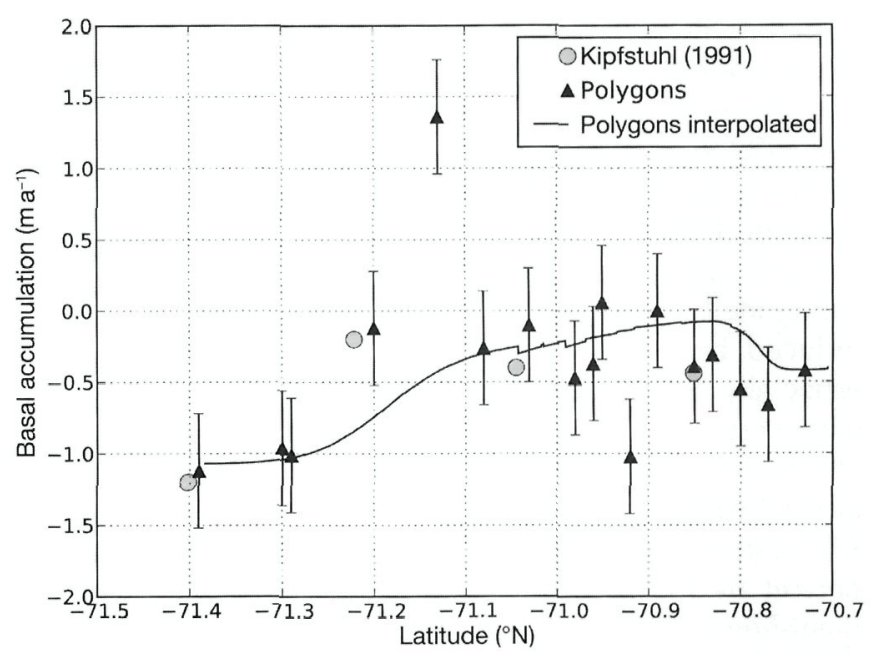

Fig. 4. Comparison between estimated basal accumulation of each polygon and interpolated values. The profile follows the estimates made by Kipfstuhl (1991). Error bars indicate the standard deviation between the data points and the interpolated field.

of velocity and ice thickness it is more important to capture the relative changes accurately. Small relative errors of incoming and outgoing mass flux add up to a larger error for the residual mass flux in the spatial derivative. This problem can be treated either by minimizing the errors in the input data or by averaging the data to a larger cell size. In this study, the latter is achieved by choosing larger polygons at the cost of spatial resolution. In order to minimize uncertainties in the input data, polygons were chosen along the RES lines, which avoids artificially introduced interpolation errors in the ice thickness data. Similarly to Seroussi and others (2011) and Morlighem and others (2011) we noticed that this problem is not negligible, because the resulting maps of basal melt rates significantly depend on the applied interpolation scheme and grid spacing. Errors in flow velocities, ice thickness and snow accumulation must be considered separately and independently of the specific implementation for the spatial derivative.

The interferometrically derived surface velocities may be flawed for a variety of reasons, including an erroneous elevation model, uncertainties in baseline estimates, atmospheric path delays and tide-induced phase ramps. We have relatively good ground-truth data to evaluate the overall accuracy of the flow field. It seems unlikely that atmospheric effects could induce errors on a smaller spatial scale than the average spacing of the velocity GCPs shown in Figure $1 \mathrm{~b}$. However, systematic errors depending on the processing history remain and cannot be reduced by averaging the flow

Table 3. Deviation of basal melt rates compared to previous studies (304, 505, 705, 905: Kipfstuhl 1991; NM: Neumayer from Lambrecht and others 1995). The locations of reference points are shown in Figure 3. For error estimates see text and Figure 4

\begin{tabular}{lrrrrr}
\hline & 304 & 505 & 705 & 905 & NM \\
\hline Previous studies $\left(\mathrm{m} \mathrm{a}^{-1}\right)$ & 0.44 & 0.40 & 0.20 & 1.20 & 0.93 \\
This study $\left(\mathrm{m} \mathrm{a}^{-1}\right)$ & 0.39 & 0.37 & 0.10 & 1.10 & 1.08 \\
Difference $\left(\mathrm{m} \mathrm{a}^{-1}\right)$ & -0.05 & -0.03 & -0.10 & -0.10 & 0.15 \\
\hline
\end{tabular}


velocities along the perimeter of the polygons. Based on the GCPs, we estimate a mean error and standard deviation of $4 \pm 18 \mathrm{~m} \mathrm{a}^{-1}$ in magnitude for the satellite-derived velocities.

Similar arguments apply to the RES data. Using ice thickness data from different RES campaigns employing different RES systems and requiring different processing schemes may lead to offsets between the flight-lines. Additionally, the manual and subjective removal of effects induced by crevasses increases the uncertainties. This is especially the case for the western part of the ice shelf where crevasses are also evident in ERS imagery (Müller and others, 2000). As the ice thickness data are only interpolated along the RES flight-lines, erroneous offsets from the different RES systems would remain. We evaluated the ice thickness dataset by means of a crossover analysis of the different flight-lines. This results in a mean and standard deviation of $0.6 \pm 18 \mathrm{~m}$.

The overall error in residual mass flux, $F$, can be roughly estimated by the individual errors of the input datasets. If the data are not averaged beforehand, the absolute errors may add up during the summation of incoming and outgoing fluxes, leading to an accumulated error for the residual mass flux which is usually much larger than $F$. Spatial averaging of the input datasets is therefore necessary.

Averaging reduces the noise in the input data but does not diminish systematic errors. In our approach, the degree of averaging is basically given by the size of the polygons. In the following back-of-the-envelope calculation we estimate the random errors in velocity and ice thickness with the previously derived standard deviations of $18 \mathrm{ma}^{-1}$ and $18 \mathrm{~m}$, respectively. We have no direct evidence for the magnitude of systematic errors and estimate $5 \mathrm{ma}^{-1}$ and $10 \mathrm{~m}$ in ice thickness to account for offsets introduced by the various systems. In a best-case scenario for averaging, the random errors decrease in proportion to the squareroot of the number of averaged data points. In our case, a typical polygon is formed by four intersecting RES lines with a total perimeter of $30 \mathrm{~km}$ containing 300 data points of ice thickness and velocity. If we consider the four sides separately, the summation along the individual lines reduces the random component by a factor of seven, leaving a random error of only a few percent for the average value of the flux field, $\mathbf{v H}$. Systematic errors may or may not be present between the four sides of the polygons. In the unfavorable case that all four sides are affected by the systematic errors described above, the error in differencing between the individual sides of the polygons may be $12 \%$ for the average changes in $\mathbf{v} H$. In terms of basal melting, errors in snow accumulation increase the error. Assuming an average snow accumulation rate of $274 \mathrm{~kg} \mathrm{~m}^{-2} \mathrm{a}^{-1}$ and a standard deviation of $21.1 \mathrm{~kg} \mathrm{~m}^{-2} \mathrm{a}^{-1}$ an overall error of $20 \%$ is estimated for $\dot{a}_{b}$ for a typical polygon in the center of the ice shelf.

In Figure 4 our estimate of basal melting is plotted against latitude to facilitate comparison with the estimates made by Kipfstuhl (1991) (profile shown as dashed white line in Fig. 3). Next to the estimated melt rates for each polygon along this profile (triangles), we show the interpolated basal melt rate (black curve). The local outlier at $\sim-71.15^{\circ} \mathrm{N}$ is related to a small discontinuity in the mosaicked velocity field, while the outlier at $\sim-70.9^{\circ} \mathrm{N}$ can be explained by an inaccuracy in the ice thickness dataset due to surface crevasses in the western part of the respective polygon. Figure 4 shows that the interpolated basal melt strongly smooths the variability in melt rates between neighboring boxes. The standard deviation between the data points and the interpolated field is $0.4 \mathrm{ma}^{-1}$. This variability of the (detrended) polygons gives an upper estimate of errors for the basal melt rates, assuming that melting is more or less homogeneous between neighboring polygons. However, the difference between our estimates and previous studies is smaller (Table 3).

The dashed white circle in Figure 3 marks an area with basal accumulation of $\sim 0.16 \mathrm{ma}^{-1}$, which suggests the accretion of ice. The crossover analysis of the RES profiles shows no irregularities in this region, and no outliers are found in the velocity field. Unlike the rest of the ice shelf, the flow regime in this area is compressive. This is also the case in the modeled flow velocities of Sandhäger (2000), who identifies the Neumayer ice rumple at the shelf ice front as the primary reason for the compression. Although we cannot exclude the presence of marine ice, it seems more likely that the apparent accretion of ice is actually related to the changing flow regime which potentially violates the steadystate assumption in this area.

In this study, temporal variations are not taken into account. The surface velocity field is based on ERS SAR data, acquired during 1994-97 and has been adjusted with in situ velocity measurements from $1979-87$ and 2007 . The ice thickness grid consists of RES measurements from airborne campaigns between 1996 and 2006 and the snow accumulation map is interpolated from firn- and ice cores from which snow accumulation data date back to 1800. Apart from the snow accumulation (Isaksson and others, 1996), temporal variations cannot be detected in the input datasets because of uncertainties in the individual methods. Under the assumption of steady state, it is justified to use datasets from different time periods. We have no way to check this assumption except for one in situ measurement (Table 3). Comparison between our estimate and the ultrasonic echosounder measurement shows a difference of only $0.15 \mathrm{~m} \mathrm{a}^{-1}$, which is well within the given error estimates.

An accurate estimate of the spatial variability in basal mass balance is an important input for ice-flow models which consider the role of ice shelves in buttressing the main ice flow from the Antarctic continent. This is the case for ice shelves which are laterally confined and/or which enclose locally grounded pinning points and ice rises. The feedback between melting and buttressing is complex, and subject to ongoing modeling efforts for which a spatially averaged melt rate beneath the ice shelf is inadequate (Gagliardini and others, 2010).

Similarly to observations in studies of other ice shelves (Rignot and Jacobs, 2002; Humbert, 2010; Wen and others, 2010) we find higher melt rates in the region where channeled inflow glaciers cross the grounding line. Our estimates in this region are solely based on flux gates, $\sim 10-30 \mathrm{~km}$ apart. Basal melt rates of the adjacent Fimbulisen range from $10-15 \mathrm{ma}^{-1}$ where Jutulstraumen crosses the grounding line, to $<0.6 \mathrm{~m} \mathrm{a}^{-1}$ in slower-moving parts of the ice shelf (Smedsrud and others, 2006; Humbert, 2010). The observed differences of about one order of magnitude in the tidal flexure zone of both ice shelves may be related to differences in ice thickness and morphology. The ice thickness of Jutulstraumen exceeds that of the Ekström Ice Shelf, $\sim 600 \mathrm{~m}$ in this region, which implies a lower melting point (Rignot and others, 2004). However, further away from the grounding line both ice shelves show similar basal melt rates. 


\section{CONCLUSION}

We have estimated melt rates beneath the Ekström Ice Shelf based on the mass-continuity assumption and flux divergence. Interferometrically derived surface velocities, RES ice thickness measurements and interpolated snow accumulation data served as main input datasets. By differentiating between systematic and random errors we estimate an expected accuracy of our method dependent on the chosen polygon size. It is inherent to our approach that uncertainties in basal melt rates strongly increase with decreasing areas under consideration. For small ice shelves, like the Ekström Ice Shelf, strong spatial averaging of the input data is not possible, which puts high demands on the quality and accuracy of the input data. Relatively small inaccuracies in the input data are amplified by the spatial derivative in the continuity equation. In order to overcome additional uncertainties caused by the interpolation of ice thickness data we calculated the mass flux exactly along narrowly spaced RES lines. Accretion of basal ice is not believed to be present at the Ekström Ice Shelf, and its occurrence in the final basal mass-balance map is related to inaccuracies in the datasets or a violation of the steady-state assumption; however, overall our estimates are in good agreement with previous studies and may serve as a baseline for further monitoring of temporal changes in basal melt.

\section{ACKNOWLEDGEMENTS}

We thank D. Jansen for providing background literature, S. Ligtenberg, M. Helsen and M. van den Broeke for information about depth and density of the firn layer and J. Griggs and J. Bamber for the ice-shelf thickness from satellite radar altimetry. We also thank the Scientific Editor F. Straneo, O. Marsh and two anonymous reviewers for improving the manuscript. Preparation of this work was supported by a scholarship of the Evangelisches Studienwerk e.V. Villigst to R.D., and during an internship at Gateway Antarctica. We appreciate helpful discussions with O. Eisen. ERS data were made available through European Space Agency Project AO3.108.

\section{REFERENCES}

Bamber JL, Gomez-Dans JL and Griggs JA (2009) A new 1 km digital elevation model of the Antarctic derived from combined satellite radar and laser data - Part 1: data and methods. Cryosphere, 3(1), 101-111

Bindschadler R and 17 others (2011) Getting around Antarctica: new high-resolution mappings of the grounded and freely-floating boundaries of the Antarctic ice sheet created for the International Polar Year. Cryosphere, 5(3), 569-588 (doi: 10.5194/tc-5-5692011)

Blindow N (1994) The central part of the Filchner-Ronne Ice Shelf, Antarctica: internal structures revealed by $40 \mathrm{MHz}$ monopulse RES. Ann. Glaciol., 20, 365-371

Corr HFJ, Jenkins A, Nicholls KW and Doake CSM (2002) Precise measurement of changes in ice-shelf thickness by phase-sensitive radar to determine basal melt rates. Geophys. Res. Lett., 29(8), 1232 (doi: 10.1029/2001GL014618)

Drews R, Rack W, Wesche C and Helm V (2009) A spatially adjusted elevation model in Dronning Maud Land, Antarctica, based on differential SAR Interferometry, IEEE Trans. Geosci. Remote Sens., 47(8), 2501-2509

Fernandoy $F$, Meyer $\mathrm{H}$, Oerter $\mathrm{H}$, Wilhelms $\mathrm{F}$, Graf $\mathrm{W}$ and Schwander J (2010) Temporal and spatial variation of stable-isotope ratios and accumulation rates in the hinterland of Neumayer station, East Antarctica. J. Glaciol., 56(198), 673-687 (doi: 10.3189/002214310793146296)

Fricker HA, Popov S, Allison I and Young N (2001) Distribution of marine ice beneath the Amery Ice Shelf. Geophys. Res. Lett., 28(11), 2241-2244 (doi: 10.1029/2000GL012461)

Gagliardini O, Durand G, Zwinger T, Hindmarsh RCA and Le Meur E (2010) Coupling of ice-shelf melting and buttressing is a key process in ice-sheets dynamics. Geophys. Res. Lett., 37(14), L14501 (doi: 10.1029/2010GL043334)

Gille ST (2008) Decadal-scale temperature trends in the southern hemisphere ocean. J. Climate, 21(18), 4749-4765 (doi: 10.1175/2008JCLI2131.1)

Griggs JA and Bamber JL (2011) Antarctic ice-shelf thickness from satellite radar altimetry. J. Glaciol., 57(203), 485-498 (doi: 10.3189/002214311796905659)

Haran T, Bohlander J, Scambos T, Painter T and Fahnestock M (2006) MODIS mosaic of Antarctica (MOA) image map. National Snow and Ice Data Center, Boulder, CO. Digital media: http://nsidc.org/data/moa/

Hellmer HH (2004) Impact of Antarctic ice shelf basal melting on sea ice and deep ocean properties. Geophys. Res. Lett., 31(10), L10307 (doi: 10.1029/2004GL019506)

Hinze H (1990) Zum Einsatz von Satelliten-Positionierungsverfahren für glaziologische Aufgaben in der Antarktis. Wiss. Arbeit. Fachricht. Vermess. Univ. Hannover 163 (hdl:10013/epic.11967)

Holland PR, Jenkins A and Holland DM (2008) The response of ice shelf basal melting to variations in ocean temperature. J. Climate, 21(11), 2558-2572 (doi: 10.1175/2007JCLI1909.1)

Humbert A (2010) The temperature regime of Fimbulisen, Antarctica. Ann. Glaciol., 51(55), 56-64 (doi: 10.3189/ 172756410791392673)

Isaksson E, Karlén W, Gundestrup N, Mayewski P, Whitlow S and Twickler M (1996) A century of accumulation and temperature changes in Dronning Maud Land, Antarctica. J. Geophys. Res., 101(D3), 7085-7094 (doi: 10.1029/95JD03232)

Jenkins A and Doake CSM (1991) Ice-ocean interaction on Ronne Ice Shelf, Antarctica. J. Geophys. Res., 96(C1), 791-813 (doi: 10.1029/90JC01952)

Jenkins A and 6 others (2010) Observations beneath Pine Island Glacier in West Antarctica and implications for its retreat. Nature Geosci., 3(7), 468-472 (doi: 10.1038/ngeo890)

Joughin I and Padman L (2003) Melting and freezing beneath Filchner-Ronne Ice Shelf, Antarctica. Geophys. Res. Lett., 30(9), 1477-1480 (doi: 10.1029/2003GL016941)

Joughin IR, Kwok R and Fahnestock MA (1998) Interferometric estimation of three-dimensional ice-flow using ascending and descending passes. IEEE Trans. Geosci. Remote Sens., 36(1), 25-37 (doi: 10.1109/36.655315)

Kipfstuhl J (1991) Zur Entstehung von Unterwassereis und das Wachstum und die Energiebilanz des Meereises in der Atka Bucht, Antarktis. Ber. Polarforsch. 85. (hdl:10013/epic.10085.d001)

König-Langlo G and Loose B (2007) The meteorological observatory at Neumayer Stations (GvN and NM-II) Antarctica. Ber. Polarforsch/Rep. Pol. Res., 76(1-2), 25-38 (hdl:10013/ epic.28566.d001)

Lambrecht A, Nixdorf U and Zürn W (1995) Ablation rates under the Ekström Ice Shelf deduced from different methods. FRISP Rep. 9, 50-56

Lambrecht A, Sandhager H, Vaughan DG and Mayer C (2007) New ice thickness maps of Filchner-Ronne Ice Shelf, Antarctica, with specific focus on grounding lines and marine ice. Antarct. Sci., 19(4), 521-532 (doi: 10.1017/S0954102007000661)

Ligtenberg SRM, Helsen MM and Van den Broeke MR (2011) An improved semi-empirical model for the densification of Antarctic firn. Cryosphere, 5(4), 809-819 (doi: 10.5194/tc-5-809-2011)

Little CM, Gnanadesikan A and Oppenheimer M (2009) How ice shelf morphology controls basal melting. J. Geophys. Res., 114(C12), C12007 (doi: 10.1029/2008JC005197) 
Morlighem M, Rignot E, Seroussi H, Larour E, Ben Dhia H and Aubry D (2011) A mass conservation approach for mapping glacier ice thickness. Geophys. Res. Lett., 38(19), L19503 (doi: 10.1029/2011GL048659)

Müller U, Sandhäger H, Sievers J and Blindow N (2000) Glaciokinematic analysis of ERS-1/2 SAR data of the Antarctic ice shelf Ekströmisen and the adjoining inland ice sheet. Polarforschung, 67(1-2), 15-26

Nicolaus M and Grosfeld K (2002) Ice-ocean interaction underneath the Antarctic ice shelf Ekströmisen. Polarforschung, 72(1), 17-29 (hdl:10013/epic.21552.d001)

Nixdorf U, Oerter H and Miller H (1994) First access to the ocean beneath Ekströmisen, Antarctica, by means of hot-water drilling. Ann. Glaciol., 20, 110-114

Nixdorf U, Lambrecht A and Steinhage D (1997) Geophysicalglaciological studies in the grounding zone area of the Ekström Ice Shelf (EIS). FRISP Rep. 11, 51-54

Payne AJ, Vieli A, Shepherd A, Wingham DJ and Rignot E (2004) Recent dramatic thinning of largest West Antarctic ice stream triggered by oceans. Geophys. Res. Lett., 31(23), L23401 (doi: 10.1029/2004GL021284)

Riedel B and Vogel D (1998) Geodätische Messungen an der Grounding Line des Ekström-Schelfeises. Ber. Polarforsch/Rep. Pol. Res. 267, 125-131

Rignot E and Jacobs SS (2002) Rapid bottom melting widespread near Antarctic ice sheet grounding lines. Science, 296(5575), 2020-2023 (doi: 10.1126/science.1070942)

Rignot E and 11 others (2004) Improved estimation of the mass balance of the glaciers draining into the Amundsen Sea sector of West Antarctica from the CECS/NASA 2002 campaign. Ann. Glaciol., 39, 231-237 (doi: 10.3189/172756404781813916)

Rignot E, Mouginot J and Scheuchl B (2011) Antarctic grounding line mapping from differential satellite radar interferometry. Geophys. Res. Lett., 38(10), L10504 (doi: 10.1029/2011GL047109)

Rotschky G and 6 others (2007) A new surface accumulation map for western Dronning Maud Land, Antarctica, from interpolation of point measurements. J. Glaciol., 53(182), 385-398 (doi: $10.3189 / 002214307783258459)$

Sandhäger H (2000) Quantifizierung eisdynamischer und massenhaushaltsrelevanter Basisgrössen eines antarktischen Inlandeis-Schelfeis-Systems unter Einsatz eines numerischen Fliessmodells. (PhD thesis, Westfälische Wilhelms-Universität Münster)
Sandhäger H and Blindow N (2000) Surface elevation, ice thickness, and subglacial-bedrock topography of Ekström Ice Shelf (Antarctica) and its catchment area. Ann. Glaciol., 30, 6168 (doi: 10.3189/172756400781820723)

Schlosser E, Oerter H and Graf W (1999) Surface mass balance investigations on Ekströmisen, Antarctica, 1980-1996. Ber. Polarforsch/Rep. Pol. Res. 313

Seroussi $\mathrm{H}$ and 6 others (2011) Ice flux divergence anomalies on 79north Glacier, Greenland. Geophys. Res. Lett., 38(9), L09501 (doi: 10.1029/2011GL047338)

Smedsrud LH, Jenkin A, Holland DM and Nost OA (2006) Modeling ocean processes below Fimbulisen, Antarctica. J. Geophys. Res., 111(C1), C01007 (doi: 10.1029/2005JC002915)

Steinhage D, Nixdorf U, Meyer U and Miller H (1999) New maps of the ice thickness and subglacial topography in Dronning Maud Land, Antarctica, determined by means of airborne radioecho sounding. Ann. Glaciol., 29, 267-272 (doi: 10.3189/ 172756499781821409)

Steinhage D, Nixdorf U, Meyer U and Miller H (2001) Subglacial topography and internal structure of central, western Dronning Maud Land, Antarctica, determined from airborne radio echo sounding. J. Appl. Geophys., 47(3-4), 183-189 (doi: 10.1016/S0926-9851(01)00063-5)

Sykes HJ, Murray T and Luckman A (2009) The location of the grounding zone of the Evans Ice Stream, Antarctica, investigated using SAR interferometry and modelling. Ann. Glaciol., 50(52), 35-40 (doi: 10.3189/172756409789624292)

Thyssen F (1988) Special aspects of the central part of FilchnerRonne Ice Shelf, Antarctica. Ann. Glaciol., 11, 173-179

Thyssen F and Grosfeld K (1988) Ekström Ice Shelf, Antarctica. Ann. Glaciol., 11, 180-183

Wen J, Wang Y, Wang W, Jezek KC, Liu H and Allison I (2010) Basal melting and freezing under the Amery Ice Shelf, East Antarctica. J. Glaciol., 56(195), 81-90 (doi: 10.3189/002214310791190820)

Werner LC, Wegmüller U, Strozzi T and Wiesmann A (2000) Gamma SAR and interferometric processing software. In Proceedings of ERS-ENVISAT Symposium, 16-20 October 2000, Gothenburg, Sweden. European Space Agency, Noordwijk, 16 20 (ESA SP-461)

Wesche C (2009) Evaluation and application of GPS and altimetry data over central Dronning Maud Land, Antarctica: annual elevation change, a digital elevation model, and surface flow velocity. (PhD thesis, University of Bremen) 